\title{
OS DESAFIOS DA UNIÃO EUROPEIA EM MATÉRIA DE PROTEÇÃO AOS REFUGIADOS
}

\author{
THE EUROPEAN UNION'S CHALLENGES ON REFUGEE PROTECTION
}

\begin{abstract}
André Ricci de Amorim
Doutorando em Direito Internacional pela Universidade do Estado do Rio de Janeiro. Mestre em Direito Internacional Público e Europeu pela Universidade de Coimbra, Portugal. Bacharel em Direito pela Universidade Federal do Rio de Janeiro. Pesquisador no Grupo de Pesquisa de Direito Internacional da Universidade Federal do Rio de Janeiro. Advogado e Professor Universitário. E-mail: andrericci_8@hotmail.com
\end{abstract}

Recebido em: 31/10/2018

Aprovado em: 13/03/2020

RESUMO: A despeito de todo esforço em desenvolver um sistema comum de asilo para os Estados-Membros da União Europeia, a aplicação dos critérios nem sempre é algo fácil de ser alcançando. Portanto, o escopo do presente trabalho é analisar o Regulamento Dublin III que define qual será o Estado-Membro responsável pela análise do pedido de asilo. Ademais, serão analisadas as medidas adotadas nos últimos anos pela União Europeia a fim ajudar determinados EstadosMembros a superarem a grande demanda de análise dos pedidos. $\mathrm{O}$ objetivo geral é permitir ao leitor a compreensão, ainda que de forma não exaustiva, do acolhimento estampado no Regulamento Dublin III. O objetivo específico é entender a importância de uma política comum de asilo no âmbito da União Europeia. Por fim, o trabalho utiliza métodos bibliográficos como Convenções Internacionais e instrumentos jurídicos comunitários europeus que permitem melhor percepção sobre a realidade do asilo na União Europeia.

Palavras-chave: Direito de Asilo. Política da União Europeia para proteção aos Refugiados. Refugiados. Regulamento Dublin III.

ABSTRACT: Despite all efforts to develop a common asylum system for European Union Member States, the application of the criteria is not always easy to achieve. Therefore, the scope of this article is to examine the Dublin III Regulation which defines the Member State responsible for examining the application for asylum. In addition, the measures adopted in recent years by the European Union to help certain Member States to overcome the great demand for analysis of applications will be examined. The general objective is to enable the reader to understand, albeit non-exhaustively, the reception of the Dublin III Regulation. The specific objective is to understand the importance of a common asylum policy within the European Union. Finally, the work uses bibliographic methods such as International Conventions and European Union legal instruments in order to allow a better perception of the reality of asylum in the European Union.

Keywords: Dublin III Regulation. European Union Policies for Refugee Protection. Refugees. Right of Asylum. 
SUMÁRIO: Introdução. 1 O histórico do direito de asilo na União Europeia e o Regulamento Dublin III. 2 Algumas medidas da União Europeia em matéria de asilo. 3 A importância de uma política comum de asilo. Conclusão. Referências. Jurisprudência.

\section{INTRODUÇÃO}

O direito dos refugiados ganhou maior robustez e passou a ser discutido no âmbito do Direito Internacional principalmente após o fim da Segunda Guerra Mundial. Neste período, surgiu o principal instrumento de proteção às vítimas de perseguição: a Convenção de Genebra relativa ao Estatuto dos Refugiados de $1951^{1}$.

Posteriormente, notou-se que seria importante acabar com a limitação temporal e geográfica deste documento que fazia com que somente europeus, vítimas da Segunda Guerra Mundial, pudessem gozar do reconhecimento da condição de refugiado. Deste modo, foi assinado em Nova Iorque, em 31 de janeiro de 1967, o Protocolo Adicional Relativo ao Estatuto dos Refugiados $^{2}$.

Nesse sentido, vale ressaltar que as instituições europeias, inspiradas nesses instrumentos, também criaram os seus próprios mecanismos para a proteção aos refugiados e solicitantes de asilo.

Assim, desde o momento em que os Estados visaram o desenvolvimento do Mercado Único Europeu até a criação da União Europeia (UE), entendeu-se que seria importante suprimir as fronteiras internas para alcançar a livre circulação de bens e pessoas, bem como estabelecer uma política comum de asilo e migração (BACAIAN, 2011, p. 23).

Em todo caso, importa ressaltar que a nomenclatura utilizada pelas instituições europeias quando se referem à proteção desses migrantes forçados tende a ser "asilado", portanto, é reconhecido o direito de asilo. Tal constatação pode ser extraída a partir da análise do Tratado da União Europeia, do Tratado sobre o Funcionamento da União Europeia e da Carta de Direitos Fundamentais da União Europeia (CDFUE) que são uníssonos em mencionar a palavra "asilo" ao invés de "refúgio"3.

Deste modo, quando este trabalho se referir à proteção internacional dessas pessoas, espera-se que o leitor considere que se tomaram por base os instrumentos jurídicos europeus que tratam do tema e, portanto, reconhecem-no como direito de asilo. Ademais, destaca-se que o termo asilo quando empregado no contexto europeu se trata de uma concessão de proteção ao indivíduo em perigo, ao passo que "refugiado" é a situação jurídica de alguém que foge de seu país. Noutros termos, é possível concluir que asilo é o que o refugiado busca, ou seja, a proteção enquanto durarem as razões que o levaram a deixar seu país de origem (CIERCO, 2010, p. 15).

\footnotetext{
${ }^{1}$ ALTO COMISSARIADO DAS NAÇÕES UNIDAS PARA OS REFUGIADOS. Convenção Relativa ao Estatuto dos Refugiados (1951). Disponível em: $<$ http://www.acnur.org/t3/fileadmin/Documentos/portugues/BDL/Convencao_relativa_ao_Estatuto_dos_Refugiados. $p d f>$. Acesso em: 04 jul. 2018.

${ }^{2}$ ALTO COMISSARIADO DAS NAÇÕES UNIDAS PARA OS REFUGIADOS. Protocolo de 1967 Relativo ao Estatuto dos Refugiados. Disponível em: <http://www.acnur.org/fileadmin/Documentos/portugues/BD_Legal/Instrumentos_Internacionais/Protocolo_de_196 7.pdf>. Acesso em: 09 jul. 2018.

3 UNIÃO EUROPEIA. Tratado da União Europeia. Disponível em: <http://publications.europa.eu/resource/cellar/9e8d52e1-2c70-11e6-b497-01aa75ed71a1.0019.01/DOC_2〉. Acesso em: 07 jul. 2018; UNIÃO EUROPEIA. Tratado sobre o Funcionamento da União Europeia. Disponível em: <https://eur-lex.europa.eu/legal-content/PT/TXT/?uri=celex\%3A12012E\%2FTXT>. Acesso em: 07 jul. 2018; UNIÃO EUROPEIA. Carta de Direitos Fundamentais da União Europeia. Disponível em: 〈http://www.europarl.europa.eu/charter/pdf/text_pt.pdf>. Acesso em: 07 jul. 2018.
} 
No entanto, há de se reconhecer que no contexto latino-americano, em especial no caso brasileiro, não se pode desprezar o fato de que asilo e refúgio possuem diferentes naturezas jurídicas.

Isso ocorre, pois o direito de asilo recebeu influência de instrumentos jurídicos regionais, tais como do Tratado de Direito Penal Internacional de Montevidéu, de 23 de janeiro 1889, e da Conferência de Havana, de 20 de fevereiro 1928. Já o direito de refúgio foi consagrado a nível global (Convenção de Genebra de 1951 e o Protocolo Adicional de 1967, principalmente), embora tenha sido objeto da Lei Federal brasileira nº 9.474, de 22 de julho de 1997.

Assim, o presente manuscrito se mostra atual e de grande relevância, visto que tem se exigido cada vez mais da União Europeia medidas que promovam o acolhimento adequado aos indivíduos que fogem de perseguições que colocam em risco suas vidas.

\section{O HISTÓRICO DO DIREITO DE ASILO NA UNIÃO EUROPEIA E O REGULAMENTO DUBLIN III}

Ao longo dos anos, as instituições europeias têm demonstrado sua preocupação com a temática de proteção aos refugiados e solicitantes de asilo.

Assim, José Noronha Rodrigues (2011, p. 78-79) ressalta a importância do Conselho da Europa no sentido de que suas ações implicaram na construção de um arcabouço jurídico de proteção a esse grupo tão vulnerável, os quais se destacam: a Convenção Europeia para a Salvaguarda dos Direitos Humanos e das Liberdades Fundamentais, de 04 de novembro de 1950; quatorze Protocolos Adicionais subsequentes (foi aprovado Paris, em 20 de março de 1952, o Protocolo Adicional n ${ }^{\circ}$ 1; em Estrasburgo, em 06 de maio de 1963, o Protocolo Adicional $\mathrm{n}^{\mathrm{o}} 2$ e $3^{\text {o; }}$ em 16 de setembro de 1963, o Protocolo Adicional no 4; em 20 de janeiro de 1966, o Protocolo Adicional no 5; em 28 de abril de 1983, o Protocolo Adicional nº 6; em 22 de novembro de 1984, o Protocolo Adicional no 7; em Viena, em 19 de março de 1985, o Protocolo Adicional no 8; em Roma, em 06 de novembro de 1990, Protocolo Adicional no 9; em Estrasburgo, em 25 de março de 1992, o Protocolo Adicional no 10; em 11 de maio de 1994, o Protocolo Adicional n ${ }^{\circ}$ 11; em Roma,

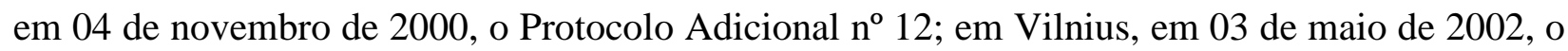
Protocolo Adicional n ${ }^{\circ}$ 13; em Estrasburgo, em 13 de maio de 2004, o Protocolo Adicional ${ }^{\circ}$ 14); Convenção Europeia sobre Extradição e o Acordo Europeu sobre o regime de circulação de pessoas entre os países membros do Conselho da Europa, ambos de 13 de dezembro de 1957.

No que tange ao Comitê de Ministros do Conselho da Europa, Rodrigues (2011, p. 78-79) continua o seu discurso citando outros instrumentos aprovados, veja-se: Recomendação sobre as medidas de detenção dos requerentes de asilo (2003); a Recomendação sobre a exclusão do estatuto de refugiado no contexto do artigo 1(F) da Convenção sobre o Estatuto dos Refugiados (2005); a Recomendação sobre as pessoas deslocadas internamente (2006).

Ato contínuo, ao discorrer sobre a atuação da Assembleia Parlamentar e/ou Assembleia Consultiva do Conselho da Europa, Rodrigues (2011, p. 78-79) também salienta a existência de outros documentos importantes, tais como: a Recomendação sobre o direito de asilo propõe a inclusão no Protocolo 2 da Convenção de 1950 (CESDHLF), de um projeto de artigo sobre o direito de asilo (1961); a Recomendação sobre a concessão do direito de asilo aos refugiados europeus (1965); a Recomendação sobre a preparação de um acordo sobre a transferência da responsabilidade para os refugiados que se deslocam legalmente de um Estado Membro do Conselho da Europa para o outro (1976); Recomendação sobre os refugiados de fato que não se enquadram dentro da Convenção de Genebra relativa aos Estatuto de refugiado (1976); a Recomendação sobre a harmonização em matéria de elegibilidade em conformidade com a Convenção de Genebra de 1951 e, com o Protocolo de 1967 (1976); a Recomendação sobre a vida e as condições de trabalho dos refugiados e requerentes de asilo (1985); a Recomendação sobre o Direito de Asilo Territorial (1988). 
Nesta ordem de ideias, ressaltam-se os documentos mencionados por Rodrigues (2011, p. 78-79) que foram elaborados a partir da década de 1990, veja-se: a Recomendação sobre a chegada dos requerentes de asilo aos aeroportos europeus (1991); a Recomendação sobre o Direito de Asilo Territorial (1994); a Recomendação sobre a situação dos requerentes de asilo cujos pedidos foram recusados (1994); a Recomendação sobre a formação dos funcionários que recebem requerentes de asilo nos postos fronteiriços (1996); a Recomendação sobre a proteção e reforço dos direitos humanos dos refugiados e requerentes de asilo na Europa (1997); a Recomendação sobre a chegada dos requerentes de asilo aos aeroportos Europeus (2000); a Recomendação sobre restrições em matéria de asilo nos Estados membros do Conselho da Europa e na União Europeia (2000); a Recomendação sobre a situação de gays e lésbicas e os seus parceiros em matéria de asilo e de imigração nos Estados Membros do Conselho da Europa (2000); a Recomendação sobre políticas comum de imigração e de asilo (2003); a Recomendação sobre o acesso à assistência e proteção dos requerentes de asilo a nível europeu nos portos e zonas costeiras (2004); a Recomendação sobre a proteção e assistência às crianças separadas que procuram asilo (2005); a Resolução sobre os requerentes de asilo e os imigrantes irregulares na Turquia (2005); a Recomendação sobre a imagem dos requerentes de asilo e os imigrantes e refugiados nos Media (2006); a Resolução sobre a política de retorno dos requerentes de asilo rejeitados/denegados na Holanda (2006); a Recomendação; e Resolução sobre a avaliação de trânsito e dos centros de processamento como uma resposta aos fluxos mistos de migrantes e requerentes de asilo (2007).

Por fim, o autor menciona que também existiram outros instrumentos jurídicos europeus que, embora não estivessem diretamente relacionados com a proteção dos refugiados, podiam ser relacionados com esta temática (RODRIGUES, 2011, p. 78-79). Alguns exemplos podem ser citados, tais como: a Recomendação relativa a certos aspectos de Direito de Asilo (1977); a Recomendação relativa aos direitos e estatuto politico dos estrangeiros (1977); a Recomendação relativa ao fundo nacional de reinstalação dos refugiados e excesso de população na Europa (1984); a Recomendação sobre a aquisição pelos refugiados da nacionalidade do país de acolhimento (1984); a Recomendação relativa a proteção temporal das pessoas obrigadas a fugir dos seus países (1997); a Recomendação sobre a situação da mulher refugiada na Europa (1998); a Recomendação sobre as condições de saúde dos imigrantes e refugiados na Europa (2001); a Recomendação sobre procedimentos de expulsão em conformidade com os direitos humanos e executados com respeito à da segurança e dignidade (2002); a Recomendação sobre a educação dos refugiados e os deslocados internos (2004); a Recomendação e Resolução sobre atividades do Alto Comissariado das Nações Unidas para os Refugiados (ACNUR) (2005); a Recomendação e a Resolução sobre os Direitos Humanos e imigrantes irregulares (2006); a Recomendação e Resolução sobre a integração das mulheres imigrantes na Europa (2006); a Resolução sobre os refugiados e pessoas deslocadas na Arménia, Azerbaijão e Geórgia (2006); a Recomendação e Resolução sobre o trabalho de imigração sobre os países da Europa Central e Oriental: situação atual e perspectivas (2006); a Recomendação e Resolução sobre a migração, refugiados e população no contexto da terceira cimeira de Chefes de Estado e de Governo dos países membros do Conselho da Europa (2006); a Recomendação sobre a situação dos refugiados e pessoas deslocadas há muito na Europa do Sudeste (2007); a Recomendação sobre o Estado, religião, segurança e direitos humanos (2007); a Recomendação e Resolução sobre avaliação de trânsito e de centros de transformação como uma resposta aos fluxos mistos de imigrantes e requerentes de asilo (2007); Recomendação sobre a situação dos trabalhadores migrantes nas agências de trabalho temporário (2007); Recomendação e Resolução sobre o estado da democracia na Europa específicos desafios que enfrentam as democracias europeias: o caso da diversidade e da migração (2008); a Recomendação sobre o estado da democracia na Europa e medidas para melhorar a participação dos migrantes (2008); a Recomendação sobre os "boat-people" na Europa: os fluxos migratórios mistos pelo mar a sul da Europa (2008); a Recomendação e Resolução sobre migrações e mobilidade na Região Eurasiático 
- Perspectivas para o futuro (2008); e, a Recomendação e Resolução sobre migração ecologicamente induzida e deslocamento: um desafio do século XXI (2009).

Ora, analisando o histórico de proteção aos refugiados no âmbito do Continente Europeu, também se faz prudente ressaltar que antes do surgimento do Mercado Único Europeu, a competência para a elaboração dos critérios de concessão de asilo era exclusivamente de cada Estado-Membro.

Isso quer dizer que até a década de 1980 cada Estado-Membro definia a sua forma de controle migratório e os elementos que seriam considerados para o reconhecimento do status de refugiado.

Conforme dito anteriormente, Bacaian (2011, p. 23) informa que essa noção começou a mudar quando os Estados passaram a buscar a livre circulação de bens e pessoas. Assim, uma das formas para se alcançar o almejado era o estabelecimento de critérios comuns em matéria de migração de pessoas e para o reconhecimento do asilo.

Assim, o início dessa transformação ocorreu ainda na década de 1990, a partir da entrada em vigor da Convenção de Dublin, em 01 de setembro de 1997. O objetivo deste instrumento jurídico comunitário precursor era determinar qual Estado-Membro seria responsável por examinar uma determinada solicitação de asilo, a fim de evitar o fenômeno do asylum shopping ${ }^{4}$.

Em todo caso, a par de tornar mais dinâmico o estudo nesta seção, optou-se por fazer um recorte temporal do direito de asilo na União Europeia remetendo ao período entre 2010 e 2014, pois diversos aspectos em matéria de asilo foram reformulados para que a interpretação dos instrumentos jurídicos seguisse certa harmonia no âmbito dos Estados-Membros.

Neste sentido, mister se faz destacar a instituição do Regulamento Dublin III, de 26 de junho de 2013, vigente até os dias atuais, que visou reformular os critérios e mecanismos de determinação do Estado-Membro responsável pela análise de um pedido de proteção internacional apresentado num dos Estados-Membros por um nacional de um país terceiro ou por um apátrida ${ }^{5}$.

De fato, as mudanças não ocorreram de forma estrutural, mas intentaram acabar com a ambiguidade acerca do tratamento dispensado aos menores não acompanhados, bem como garantir certos benefícios no tratamento destes solicitantes de asilo.

Em termos práticos, este novo Regulamento permitiu: $i$ ) a definição de conceitos até então imprecisos nos outros dois Regulamentos (Dublin I e II), tais como "representante" e "risco de fuga"; ii) a delimitação de prazos e custos do Estado-Membro envolvido na análise do pedido de asilo; iii) pela primeira vez nos Regulamentos de Dublin foi expressamente vedada a transferência de solicitantes de asilo para o Estado-Membro inicialmente designado responsável pela análise do pedido caso exista o risco de tratamento desumano ou degradante (Artigo $3^{\circ}, \mathrm{n}^{\circ} 2$, segunda parte); iv) o alargamento do conceito de "familiar", favorecendo principalmente os menores não acompanhados uma vez que permitiu que eles pudessem ser reunidos aos seus avós, tios ou tias que sejam residentes legalmente num dos Estados-Membros (Artigo $8^{\circ}, n^{\circ} 2$ ); v) a criação de um mecanismo de alerta rápido, estado de preparação e gestão de crises para com base nas informações recolhidas pelo Gabinete Europeu de Apoio em matéria de Asilo, cujo objetivo é criar medidas prévias para evitar o colapso do sistema comum de asilo aplicado por um Estado-Membro, tal como ocorreu na Grécia desde o início da recente onda migratória (Artigo 33); dentre outras melhorias (UNIÃO EUROPEIA, 2013).

Contudo, Piçarra (2016, pp. 28-29) ressalta três implicações não muito positivas deste documento. A primeira é que o Regulamento Dublin III não baseia a sua aplicação em uma política de cotas que considera aspectos como o rendimento fiscal ou a população do Estado-Membro.

\footnotetext{
${ }^{4}$ Cierco (2011, pp. 116-117) informa que o fenômeno do asylum shopping consiste no ato de um mesmo indivíduo solicitar asilo simultaneamente em vários Estados da União Europeia.

${ }^{5}$ Refere-se ao Regulamento (UE) no 604/2013 do Parlamento Europeu e do Conselho, de 26 de junho de 2013 , publicado em Jornal Oficial da União Europeia n ${ }^{\circ}$ L 180/31 de 29 de Junho de 2013. Ressalta-se que a sua entrada em vigor ocorreu em 19 de julho de 2013 (UNIÃO EUROPEIA, 2013).
}

Revista de Direito Brasileira | Florianópolis, SC | v. 28 | n. 11 | p.259-273 | Jan./Abr. 2021 
Baseando-se nisto é possível notar, de fato, a insatisfação de muitos Estados-Membros com esta política de acolhimento que não distribui de forma igualitária os solicitantes de asilo e, por isso, passam a desenvolver ações contrárias aos compromissos regionais e internacionais de defesa do direito dos refugiados.

Na Itália, por exemplo, o antigo Ministro do Interior, Matteo Salvini, causou preocupação ao prometer fechar os portos do país aos navios de ONGs que resgatassem essas pessoas no Mar Mediterrâneo alegando que as regras do Regulamento de Dublin precisam ser revistas, uma vez que, de acordo com o ministro, a Itália não tem mais condições de suportar sozinha essa questão (ZUNINO, 2018).

A segunda implicação deste Regulamento é a resistência por parte de alguns solicitantes de asilo que não são ouvidos sobre a sua preferência acerca do Estado-Membro que analisará o seu pedido de asilo. A única exceção diz respeito aos menores não acompanhados e os solicitantes que tenham algum membro da família residente em um Estado-Membro (PIÇARRA, 2016, pp. 28-29).

Acerca disto, não é difícil notar que tal resistência pode trazer efeitos negativos. Por outro lado, não se pode menoscabar que deixar a escolha do Estado-Membro responsável pela análise do pedido a cargo estritamente do solicitante poderia sobrecarregar o sistema comum de asilo de alguns Estados-Membros, como por exemplo, a Alemanha que, em razão da sua forte economia, tem atraído um grande número de refugiados ${ }^{6}$.

Por fim, a terceira consequência citada por Piçarra (2016, pp. 28-29) seria a responsabilidade desproporcional assumida por alguns Estados-Membros em razão do critério do Estado-Membro da primeira entrada.

Sobre isso, cumpre informar que atualmente está em trâmite no Parlamento Europeu uma proposta para reforma da referida Convenção (ou Regulamento) ${ }^{7}$.

Talvez por essa razão, algumas medidas foram adotadas a fim de tentar (re)equilibrar a participação dos Estados-Membros em matéria de asilo.

Deste modo, se destaca a suspensão parcial do Regulamento Dublin III, em especial, no capítulo que estabelece os critérios de determinação do Estado-Membro responsável pela análise de um pedido de proteção internacional apresentado por um nacional de um país terceiro e a aprovação do acordo entre União Europeia e Turquia, ambos a serem abordados na próxima seção.

\section{ALGUMAS MEDIDAS DA UNIÃO EUROPEIA EM MATÉRIA DE ASILO}

Embora existam as regras mínimas em matéria de asilo que devem ser adotadas pelos Estados-Membros, sobretudo, o Regulamento Dublin III, notou-se que nos últimos anos a demanda pelo reconhecimento da condição de refugiado não estava sendo harmoniosa no território da União Europeia.

Assim, seria imprudente não mencionar duas medidas adotadas que mitigaram a aplicação do referido Regulamento e visaram minimizar os efeitos deste recente fluxo migratório experimentado pelos Estados-Membros, dentre as quais se destacam as Decisões (UE) 2015/1523 e 2015/1601, bem como a polêmica Declaração UE-Turquia.

\section{a) As Decisões (UE)}

\footnotetext{
${ }^{6}$ Sobre isso ressalte que noprimeiro trimestre de 2018 o Estado-Membro da União Europeia com o maior número de solicitantes de asilo que formularam o pedido pela primeira vez foi registado na Alemanha, seguido pela França, Itália, Grécia e Espanha (EUROSTAT. Asylumquarterlyreport 2018. Disponível em: <http://ec.europa.eu/eurostat/statisticsexplained/index.php/Asylum_quarterly_report>. Acesso em: 11 jul. 2018).

${ }^{7}$ UNIÃO EUROPEIA. Regras do sistema de asilo da UE: a posição do Parlamento sobre a reforma da regulação de Dublin. Disponível em: <https://www.europarl.europa.eu/news/pt/headlines/world/20180615STO05927/regras-doasilo-da-ue-posicao-do-parlamento-sobre-a-reforma-da-regulacao-dublin >. Acesso em: 13 mar. 2020.
} 
Primeiramente, importa citar a Decisão (UE) 2015/1523 do Conselho, de 14 de setembro de 2015 e a Decisão (UE) 2015/1601 do Conselho, de 22 de setembro de 2015, ambas com objetivo de estabelecer medidas provisórias no domínio da proteção internacional a favor da Itália e da Grécia, a fim de ajudar estes Estados-Membros a enfrentarem melhor uma situação de emergência caracterizada por um súbito afluxo de nacionais de países terceiros ${ }^{8}$.

Sobre essa questão, a mais polêmica foi, sem dúvidas, a Decisão (UE) 2015/1601 que encontrou resistência em alguns Estados-Membros que se recusaram a participar do programa de recolocação de solicitantes de asilo. Isto foi o que ocorreu, por exemplo, na Polônia e na Hungria que, no caso deste último, realizou um referendo cujo resultado foi a rejeição das condições estabelecidas nesta Diretiva.

Além disso, há de se considerar que a rejeição também se deu no âmbito jurídicoprocessual, pois a Eslováquia e a Hungria ${ }^{9}$ interpuseram recursos ao Tribunal de Justiça da União Europeia (TJUE) para anulação desta decisão (TRIBUNAL DE JUSTIÇA DA UNIÃO EUROPEIA, 2017).

No caso do recurso eslovaco, a fundamentação se firmou na violação das formalidades essenciais previstas nos Artigos 78(3) e 293, ambos do Tratado de Formação da União Europeia (TFUE); e dos Artigos 10(1)(2) e 13(2)do Tratado da União Europeia (TUE). Ademais, suscitouse a violação aos princípios gerais da União Europeia, tais como o da proporcionalidade, democracia representativa, equilíbrio institucional e boa governança.

Já o recurso húngaro sustentou que o artigo 78(3) do TFUE não garante competência jurídica ao Conselho para adotar tal decisão e que, além disto, foram violados os princípios da necessidade, da proporcionalidade, da segurança jurídica e da clareza normativa.

A resposta do TJUE ocorreu em 06 de setembro de 2017 quando o acórdão negou provimento ao recurso e condenou ambos os países a suportarem, "além das suas próprias despesas, as despesas efetuadas pelo Conselho da União Europeia” (TRIBUNAL DE JUSTIÇA DA UNIÃO EUROPEIA, 2017).

Em todo caso, deve-se destacar que a Decisão (UE) 2015/1601 foi alterada pela Decisão (UE) 2016/1754 do Conselho, de 29 de setembro de 2016, que basicamente possibilitou a aplicação do apoio financeiro "a cada admissão legal conducente a uma redução da obrigação de recolocação" (UNIÃO EUROPEIA, 2016). Além disto, o referido instrumento inseriu o item 3-A ao Artigo $4^{\circ}$ que informa o seguinte:

\section{Artigo $4^{\circ}$}

(...)

3-A. No que se refere à recolocação dos requerentes referidos no $n .{ }^{0} 1$, alínea c), os Estados-Membros podem optar pelo cumprimento das suas obrigações através da admissão, no seu território, de nacionais sírios presentes na Turquia ao abrigo de regimes de admissão nacionais ou multilaterais legais de pessoas com clara necessidade de proteção internacional que não o regime de reinstalação que foi objeto das Conclusões dos Representantes dos Governos dos Estados-Membros, reunidos no Conselho, de 20 de julho de 2015. O número de pessoas assim admitidas por um Estado-Membro conduz a uma redução correspondente da obrigação do Estado-Membro em causa (UNIÃO EUROPEIA, 2016).

\footnotetext{
${ }^{8}$ UNIÃO EUROPEIA. Decisão (UE) 2015/1523 do Conselho, de 14 de setembro de 2015, publicada em Jornal Oficial da União Europeia $\mathrm{n}^{\circ}$ L 239/146 de 15 de Setembro de 2015. Disponível em: <http://eur-lex.europa.eu/legalcontent/PT/TXT/? uri=CELEX:32015D1523>. Acesso em: 13 jun. 2018; UNIÃO EUROPEIA. Decisão (UE) 2015/1601 do Conselho, de 22 de setembro de 2015, publicada em Jornal Oficial da União Europeia n ${ }^{\circ}$ L 248/80 de 24 de Setembro de 2015. Disponível em: <http://eur-lex.europa.eu/legalcontent/PT/TXT/?uri=CELEX\%3A32015D1601>. Acesso em: 13 jun. 2018.

${ }^{9}$ Refere-se aos processos apensos C-643/15 e C-647/15.
} 
Nesta senda, nota-se que embora exista certa rejeição às decisões por parte de alguns Estados-Membros, existem aqueles que se mostraram dispostos a colaborar, felizmente, a maioria.

Contudo, o sucesso não pode ser considerado absoluto, pois o número de recolocações ainda é muito baixo devido aos obstáculos burocráticos e, de acordo com Piçarra (2016, p. 36), em alguns casos a justificativa para tal ineficiência pode ser resultado da resistência dos próprios solicitantes de asilo contra a sua recolocação forçada.

\section{b) A Declaração UE-Turquia}

Nos últimos anos, muitos migrantes, mormente os migrantes forçados vítimas dos conflitos na Síria, utilizaram a Turquia como rota para chegar ao território da União Europeia. Por tal razão, diversos Estados-Membros, em especial a Grécia e a Bulgária, passaram a enfrentar uma sobrecarga do sistema de asilo, principalmente nas regiões fronteiriças com a chegada de milhares de pessoas todos os dias em busca de proteção internacional.

Portanto, a segunda medida que se entende por bem destacar foi o lançamento de um acordo entre a União Europeia e a Turquia. Em 18 de Março de 2016, na sequência do Plano de Ação Conjunta UE-Turquia, ativado em 29 de novembro de 2015 e da Declaração UE-Turquia de 7 de Março de 2016, a União Europeia e a Turquia chegaram a um acordo para controlar o fluxo de migrantes irregulares provenientes desde a região da Turquia até o território da União ${ }^{10}$.

Através desta cooperação, ficou firmado que: $i$ ) os novos migrantes que chegarem às ilhas gregas, a partir de 20 de Março de 2016, de forma irregular e provenientes da Turquia serão devolvidos a este país e os custos serão suportados pela UE; ii) a Turquia se compromete a envidar os melhores esforços evitar a abertura, a partir do seu território, de novas rotas de migração irregular direção à UE; iii) para cada migrante em situação irregular que retorne à Turquia, a União Europeia se compromete em reassentar um refugiado que esteja em qualquer dos campos de refugiados daquele país. Importa salientar que para dar seguimento ao plano a UE destinou inicialmente três bilhões de euros para apoio aos sírios em território turco (grupo de nacionais de maior expressividade em busca de proteção internacional atualmente) e prometeu mais três bilhões de euros até o final de 2018.

Portanto, ao analisar o seu conteúdo, nota-se que o plano de ação visava oficialmente: $i$ ) intensificar a cooperação no apoio aos refugiados sírios que se beneficiam de proteção temporária; ii) contribuir para o não desgaste das comunidades de acolhimento na Turquia; e iii) evitar os fluxos migratórios irregulares para o território da UE, uma vez que nem todos os migrantes que utilizavam a rota poderiam ser reconhecidos como refugiados à luz da Convenção de Genebra de 1951 e o Protocolo Adicional de 1967.

Em todo caso, este acordo gerou polêmica justamente por envolver a Turquia, país que não tem um histórico sólido na defesa dos direitos humanos e frequentemente é criticado pela sociedade internacional por limitar a liberdade de expressão dos seus cidadãos e dos meios de comunicação. Portanto, a preocupação é se a Turquia aplicará as regras de direito internacional humanitário que a UE reconhece no seu sistema jurídico.

Com duras críticas, Favilli (2016) argumenta que o método utilizado pela União Europeia para conter a atual crise migratória não tem demonstrado que o bloco está empenhado em resolver de forma definitiva as questões humanitárias envolvendo os refugiados, ao contrário, visa somente o retorno imediato de migrantes irregulares e solicitantes de asilo para a Turquia.

Encampando a mesma ideia, a InternationalRescueCommittee, a NorwegianRefugeeCouncil e a OXFAM International publicaram conjuntamente um documento

\footnotetext{
${ }^{10}$ A seguir esse acordo será desiganado simplesmente como Declaração, cujo plano era desenvolver uma ação conjunta a fim de minimizar os efeitos da migração via Mar Egeu (UNIÃO EUROPEIA. EU-Turkey statement, 18 March 2016. Disponível em: <http://www.consilium.europa.eu/en/press/press-releases/2016/03/18/eu-turkey-statement/>. Acesso em: 08 jul. 2018).
} 
que demonstra que, embora a Declaração tenha se firmado na ideia de acabar com o sofrimento humano, o que pode ser observado é totalmente o contrário. Isso porque, muitos solicitantes de asilo estão vivendo em condições precárias e sujeitos aos mais diversos tipos de violações, incluindo abuso sexual em troca de dinheiro e proteção (OXFAM INTERNATIONAL, 2017).

Além disto, o documento informa que as verificações médicas e outras avaliações que deveriam ser feitas para identificar e proteger as pessoas vulneráveis que chegam às ilhas não são aplicadas de forma consistente. Na ilha grega de Samos, por exemplo, há relatos de que apenas aqueles que são visivelmente vulneráveis ou facilmente identificáveis como menores não acompanhados passam por uma avaliação mais detalhada (OXFAM INTERNATIONAL, 2017).

Embora esta Declaração seja juridicamente controversa, Piçarra (2016, p. 38) acredita que esta pode ser a "medida de maior alcance para fazer face à 'crise migratória e de refugiados sem precedentes' e para viabilizar a reinstalação enquanto canal de acesso legal à UE para as pessoas carecidas de protecção internacional".

Em todo caso, qualquer que seja o verdadeiro intento da Declaração ou de futuras mediadas adotadas pela União Europeia, fundamental se faz a observância dos direitos humanos dos refugiados, conforme preconiza a Convenção de Genebra de 1951 e o Protocolo Adicional de 1967.

Isso porque, o retorno destes migrantes em situação irregular deve ser avaliado com cautela e de forma individualizada a fim de não incorrer em violações dos princípios gerais do direito, bem como os demais princípios que visam garantir a proteção daqueles que, de fato, fazem jus ao reconhecimento da condição de refugiado.

Noutros termos e em apertada síntese, a proteção deve ser no sentido de vedação ao refoulement e a garantia de não perseguição criminal.

Sobre isso, não custa aclarar que o princípio do non-refoulement implica na vedação ao retorno do refugiado ou solicitante de asilo ao seu país de origem ou de residência habitual enquanto permanecerem as circunstâncias que põem em risco sua vida, integridade física e liberdade (CIERCO, 2010).

Tal princípio é assegurado na Convenção de Genebra de 1951, no qual informa em seu Artigo 33(1) que "nenhum dos Estados Contratantes expulsará ou rechaçará, de maneira alguma, um refugiado para as fronteiras dos territórios em que a sua vida ou a sua liberdade seja ameaçada $(\ldots)^{\prime \prime 11}$.

Sem embargo, Teresa Cierco informa que essa vedação por vezes é desrespeitada pelos próprios Estados-Membros:

As medidas adoptadas pelos Estados em defesa do seu interesse legítimo de controlo da imigração irregular, colide muitas vezes com a possibilidade dos refugiados procurarem protecção. As medidas de fiscalização fronteiriça, como o controlo nas portas de desembarque e a bordo dos aviões, juntamente com os requisitos de visto, impede o acesso dos requerentes de asilo ao procedimento de determinação do estatuto e, consequentemente, resulta no seu reenvio para situações onde sua vida e liberdade estão em perigo. Estas medidas são adoptadas em vários países da Europa Ocidental (França, Alemanha, Holanda, Noruega e Espanha). Apesar instrução administrativa incluir formalmente disposições especiais para os requerentes de asilo, na prática, estas não são, por vezes, observadas. O risco de reenvio para países de origem aumenta igualmente com as deficientes condições de interpretação e de tradução, as dificuldades de acesso a

\footnotetext{
${ }^{11}$ Refere-se à Convenção Relativa ao Estatuto dos Refugiados (1951) e o conteúdo integral do Artigo 33(1) e demais se encontra disponível em: <http://www.acnur.org/t3/fileadmin/Documentos/portugues/BDL/Convencao_relativa_ao_Estatuto_dos_Refugiados. $p d f>$. Acesso em: 04 jul. 2018.
} 
apoio jurídico e a falta de informação preliminar relativa aos procedimentos de asilo (CIERCO, 2010, p. 78).

Sobre a garantia de não perseguição criminal, plasmada no Artigo 31(1) da Convenção de Genebra de 1951, a ideia é evitar a criminalização dos refugiados e solicitantes de asilo que, ao deixarem o seu local de origem, geralmente não conseguem cumprir os trâmites administrativos para entrar noutro Estado, tais como a solicitação de passaporte, visto de entrada e outros.

Acerca disto, é interessante a análise de Hathaway (1991, p. 51) que salienta que a Convenção de Genebra de 1951 não estabelece a entrada regular do indivíduo como requisito para a análise do pedido de reconhecimento da condição de refugiado.

Portanto, é mister que os Estados-Membros mantenham a atenção aos instrumentos normativos comunitários e globais em matéria de asilo e compartilhem entre si a responsabilidade de acolher essas pessoas de forma digna.

\section{A IMPORTÂNCIA DE UMA POLÍTICA COMUM DE ASILO}

Conforme informado anteriormente, a União Europeia desenvolveu um sistema jurídico comum para o tratamento e acolhimento em matéria de asilo. No entanto, desde o início da recente onda migratória de pessoas em busca de proteção, muitos Estados-Membros têm defendido ser preciso restringir de forma mais enérgica a entrada dessas pessoas no território da União.

Primeiramente, cumpre salientar que nos parece correto afirmar que ao se falar em proteção aos refugiados há de se atentar para as dimensões do seguinte binômio: solidariedade e responsabilidade.

Entendemos que a solidariedade informa que ao se deparar com seus semelhantes em situação de vulnerabilidade, espera-se que o ser humano seja movido por um sentimento de compaixão e cooperação, não se tornando insensível com a dor alheia.

De igual forma, a responsabilidade dos Estados não seve ser ignorada, ou seja, o Estado signatário da Convenção de Genebra de 1951 e o Protocolo Adicional de 1967 tem o dever de proteger os seus termos e se manter fiel ao compromisso internacional assumido. No caso da União Europeia, além destes documentos internacionais, dever-se-ia aplicar a mesma lógica no que tange aos instrumentos jurídicos comunitários.

No entanto, o avanço de ideias ultranacionalistas propaga a máxima de que essas pessoas representam um risco à sociedade. Por essa razão, Cierco faz um alerta:

(...) recessão e o desemprego, combinados com o receio dos refugiados se tornarem num 'fardo' para os sistemas de segurança social, juntamente com os sentimentos xenófobos e racistas, que normalmente são exacerbados com os fluxos em massa de refugiados, mais o risco de permanência a longo prazo, levam os Estados, sobretudo os europeus, a restringirem o asilo e a adoptar um conjunto de políticas que dificultam e entravam o acesso ao território europeu (CIERCO, 2010, p. 84).

Assim é que Haesbaerth (2010, p. 552) lembra que um mesmo país pode receber bem os migrantes altamente qualificados, mas também desenvolver legislações restritivas aos migrantes forçados, pois enxergam essas pessoas como "bárbaras" ou um "excedente perigoso" para a segurança nacional.

Vale lembrar que, no âmbito europeu, os riscos de acolher indivíduos perigosos à segurança nacional podem ser minimizados com a ajuda dos serviços de segurança e informação, como a Europol, a FRONTEX e o sistema EURODAC, cujas informações podem ser acessadas 
pelos órgãos policiais dos Estados-Membros de forma a prevenir, detectar ou investigar crimes graves ou possíveis ações de grupos terroristas ${ }^{12}$.

Ademais, não se pode menoscabar o fato de que o envolvimento com práticas criminosas é contrário aos princípios da Organização das Nações Unidas e serve de fundamento para a exclusão ao reconhecimento da condição de refugiado, conforme Artigo $1^{\circ}(\mathrm{F})(\mathrm{c})$ da Convenção de Genebra de 1951.

Sobre isso, Goodwin-Gill e Mc Adam (2007, p. 197) ressaltam que tal exclusão será cabível quando for possível identificar o ato praticado e desde que o Estado observe o devido processo legal e suas obrigações gerais de Direito Internacional.

Em todo caso, não há qualquer pretensão de que a adoção dessas precauções representariam meios infalíveis de controle da segurança. No entanto, é fundamental que os Estados-Membros se comprometam em observar as normas de proteção aos refugiados e compartilhem a responsabilidade de forma igualitária. Caso contrário, algumas consequências danosas poderão surgir e, por isso, destacam-se a seguir pelo menos três.

A primeira delas é, conforme destacado por Cierco (2010), o afloramento de discursos xenófobos e de intolerância aos migrantes, sejam eles econômicos ou forçados, que muitas vezes são colocados no mesmo patamar, embora tenham direitos contemplados em diferentes instrumentos jurídicos.

O segundo efeito é o enfraquecimento da proteção dos direitos dos refugiados no âmbito dos Estados-Membros, pois ao adotarem regras diferentes em cada Estado aumenta-se o risco de perda da eficácia da norma jurídica.

Tais concepções podem ser observadas, por exemplo, quando se nota a crítica de alguns Estados-Membros ao Regulamento Dublin III e, mesmo após a edição das Decisões citadas no tópico anterior, restringem a entrada de migrantes em seu território.

Ora, de certa forma é compreensível a queixa destes países, pois em nenhum trecho do Regulamento existe margem para considerar que aspectos como o número de habitantes do EstadoMembro e o seu Produto Interno Bruto (PIB) deverão ser considerados.

Em todo caso, este fato não pode servir de condão para desacreditar na política comum de asilo, pois este instrumento permitiu dois avanços, quais sejam: $i$ ) determinar qual Estado-Membro é o responsável pela análise do pedido de um requerente de asilo; e ii) que apenas um EstadoMembro proceda na análise de cada pedido de asilo, evitando tanto o aumento dos gastos públicos, quanto o fenômeno do asylum shopping ${ }^{13}$.

Por fim, a dificuldade em garantir o acesso a um sistema comum de asilo em que se respeitam os direitos dos refugiados pode trazer a terceira consequência perniciosa: a dificuldade de se promover a integração local destas pessoas.

Neste sentido, Crisp (2004, p. 1) defende que a integração dos refugiados deve ser analisada sob a ótica de suas três dimensões.

A primeira se trata de um processo jurídico, através do qual os refugiados possam alcançar uma gama mais alargada de direitos no Estado acolhedor. Em seguida, trata-se de um processo econômico, que consiste em estabelecer meios de subsistência sustentáveis para depender cada vez menos do auxílio estatal ou de apoio humanitário. Por fim, mas não menos importante, observa-se o processo social e cultural de adaptação e aceitação do refugiado na comunidade local sem que este viva com temor de discriminação, indimidação ou exploração; ou seja, que o refugiado se sinta parte do grupo em que está inserido (CRISP, 2004, p. 1).

Sobre isso, Jacobsen (2001, p. 9) contribui com o discurso de Crisp ao informar que somente será possível a integração do refugiado com a comunidade local quando o mesmo: $i$ ) não

\footnotetext{
${ }^{12}$ O EURADAC, por exemplo, Instituído através do Regulamento (CE) no 2725/2000 do Conselho, de 11 de Dezembro de 2000. O sistema está em funcionamento desde 15 de Janeiro de 2003 e além dos Estados-Membros fazerem parte do programa, também estão inseridos: Islândia, Noruega e Suécia.

${ }^{13}$ Sobre o asylum shopping, vide nota de rodapé $\mathrm{n}^{\mathrm{o}} 4$.
}

Revista de Direito Brasileira | Florianópolis, SC | v. 28 | n. 11 | p.259-273 | Jan./Abr. 2021 
está em perigo físico (e não vive sob a ameaça de refoulement); ii) não está confinado em acampamentos ou assentamentos e tem o direito de regressar ao seu país de origem; iii) pode sustentar a si próprio e sua família; $i v$ ) tem acesso ao sistema de ensino ou formação profissional, instalações de saúde e habitação; $v$ ) está socialmente conectado com a comunidade acolhedora e há pouca distinção entre o seu padrão de vida e dos nacionais.

Portanto, a solução para a questão do atual fluxo migratório na União Europeia somente será alcançada a partir da observância dos critérios mínimos comunitários em matéria de asilo. Em outras palavras, não acreditamos que o isolamento geográfico ou a negação de assistência àqueles que cruzam o Mediterrâneo (ou fronteiras terrestres) será a melhor solução para dar fim aos problemas internos dos Estados-Membros em matéria de asilo.

\section{CONCLUSÃO}

O aumento do fluxo migratório de refugiados representa um verdadeiro desafio para a União Europeia. Isso porque, ao mesmo tempo em que aos Estados acolhedores se veem com a responsabilidade de proteger essas pessoas ao seguirem normas comuns, também não desejam estimular a entrada de pessoas em seus territórios de forma desordenada, pois dentre os refugiados existem também os migrantes econômicos que tentam se valer do instituto como medida desesperada por uma vida melhor.

Neste sentido, o esforço da União Europeia em criar um sistema comum de asilo que respeite os direitos dos refugiados e permita o desenvolvimento de programas voltados para a integração local dessas pessoas, embora passível de críticas, se mostra em constante desenvolvimento.

De fato, as demandas em matéria de asilo não afetam os Estados-Membros uniformemente. Assim, o desafio da União Europeia é grande e, por isso, poderia ser interessante se pensar no aprimoramento de alguns aspectos, tais como:

a) Estímulo aos mecanismos que garantam a aplicação de padrões mínimos de tratamento e proteção em matéria de asilo em todos os Estados-Membros;

b) Reforço da solidariedade entre os Estados-Membros que enfrentam situação de emergência no seu território devido ao aumento das solicitações de asilo, de modo que a responsabilidade pelo acolhimento seja compartilhada e não fique a cargo de poucos Estados;

c) Reforma do Regulamento Dublin III no sentido de modificar as regras para análise de pedidos de refúgio no bloco, passando a considerar também aspectos como o número de habitantes do país e o seu Produto Interno Bruto (PIB);

Em todo caso, não há qualquer pretensão de que as medidas sugeridas neste trabalho são exaustivas ou fundamentais, isoladamente, para a solução da questão migratória na União Europeia. Ao contrário, espera-se que essas ações sirvam ao menos como alavancas para o avanço da política comum de asilo.

Enfim, o que se pode notar é que as dificuldades em enfrentar a questão do massivo fluxo de migrantes forçados têm muita relação com uma resistência política e ideológica dos Estados e não somente com a escassez de recursos e/ou de instrumentos jurídicos comunitários europeus.

\section{REFERÊNCIAS}

ALTO COMISSARIADO DAS NAÇÕES UNIDAS PARA OS REFUGIADOS. Convenção Relativa ao Estatuto dos Refugiados (1951). Disponível em: 
<http://www.acnur.org/t3/fileadmin/Documentos/portugues/BDL/Convencao_relativa_ao_Estatu to_dos_Refugiados.pdf>. Acesso em: 04 jul. 2018.

Protocolo de 1967 Relativo ao Estatuto dos Refugiados. Disponível em:

<http://www.acnur.org/fileadmin/Documentos/portugues/BD_Legal/Instrumentos_Internacionais /Protocolo_de_1967.pdf>. Acesso em: 09 jul. 2018.

BACAIAN, L. E. The protection of refugees and their right to seek asylum in the European Union.Collection Euryopa, vol. 70, 2011, pp. 1-84. Disponível em:

<https://www.unige.ch/gsi/files/6614/0351/6348/Bacaian.pdf>. Acesso em: 28 mai. 2018.

CIERCO, T. A instituição de asilo na União Europeia. Coimbra: Almedina, 2010.

CRISP, J. The local integration and local settlement of refugees: a conceptual and historical analysis. UNHCR - New Issues in Refugee Research, Working Paper, n.102, 2004, pp. 1-11. Disponível em: <http://www.unhcr.org/research/working/407d3b762/local-integration-localsettlement-refugees-conceptual-historical-analysis.html>. Acesso em: 25 mai. 2018.

EUROSTAT. Asylumquarterlyreport 2018. Disponível em:

<http://ec.europa.eu/eurostat/statistics-explained/index.php/Asylum_quarterly_report>. Acesso em: 11 jul. 2018.

FAVILLI, C. La cooperazione UE-Turchia per contenere il flusso dei migranti e richiedenti asilo: obiettivo riuscito? Il Mulino - Rivista di Diritti Umani e Diritto Internazionale, vol. 10, 2016, n. 2, pp. 405-426.

GOODWIN-GILL, G. S.; MCADAM, J. The refugee in International Law, $3^{\mathrm{a}}$ Edição, Coleção Clarendon Paperbacks. Oxford, UK: Oxford University Press, 2007.

HAESBAERTH, R. Território, insegurança e risco em tempos de contenção social. In: Póvoa Neto, H.; Ferreira, A.; Vainer, C. e Santos, M. (org.).A experiência migrante: entre deslocamentos e reconstruções. Rio de Janeiro: Garamond, 2010, pp. 537-557.

HATHAWAY, J. C. The Law of Refugee Status. Toronto: Butterworths, 1991.

JACOBSEN, K. The forgotten solution: local integration for refugees in developing countries. UNHCR - New Issues in Refugee Research, Working Paper, n. 45, 2001, pp. 1-43. Disponível em: <http://www.unhcr.org/3b7d24059.pdf>. Acesso em: 29 mai. 2018.

OXFAM INTERNATIONAL. The Reality Of The EU-Turkey Statement - How Greece has become a testing ground for policies that erode protection for refugees. Disponivel em: <https://www.oxfam.org/sites/www.oxfam.org/files/bn-eu-turkey-statement-migration-170317en.pdf>. Acesso em: 20 mai. 2018.

PIÇARRA, N. A União Europeia e a “crise migratória e de refugiados sem precedentes": crônica breve de uma ruptura do Sistema Europeu Comum de Asilo. Revista Eletrônica de Direito Público, vol. 3, n. 2, Novembro/2016, pp. 01-40.

RODRIGUES, J. N. O futuro do instituto de asilo no mundo. Revista Jurídica, CCJ, Vol. 15, nº 29, pp. 69-80, Jan./Jul., 2011. 
UNIÃO EUROPEIA. Carta de Direitos Fundamentais da União Europeia. Disponível em: <http://www.europarl.europa.eu/charter/pdf/text_pt.pdf>. Acesso em: 07 jul. 2018.

. Decisão (UE) 2015/1523 do Conselho, de 14 de setembro de 2015, publicada em Jornal Oficial da União Europeia n ${ }^{\circ}$ L 239/146 de 15 de Setembro de 2015. Disponível em: <http://eur-lex.europa.eu/legal-content/PT/TXT/?uri=CELEX:32015D1523>. Acesso em: 13 jun. 2018.

. Decisão (UE) 2015/1601 do Conselho, de 22 de setembro de 2015, publicada em Jornal Oficial da União Europeia n ${ }^{\circ}$ L 248/80 de 24 de Setembro de 2015. Disponível em: <http://eur-lex.europa.eu/legal-content/PT/TXT/?uri=CELEX\%3A32015D1601>. Acesso em: 13 jun. 2018.

. Decisão (UE) 2016/1754 do Conselho, de 29 de setembro de 2016, publicada em Jornal Oficial da União Europeia n ${ }^{\circ}$ L 268/82 de 01 de Outubro de 2016. Disponível em: <http://eur-lex.europa.eu/legal-content/PT/TXT/?uri=CELEX:32016D1754>. Acesso em: 13 jun. 2018.

. EU-Turkey statement, 18 March 2016. Disponível em:

<http://www.consilium.europa.eu/en/press/press-releases/2016/03/18/eu-turkey-statement/>. Acesso em: 08 jul. 2018.

. Regras do sistema de asilo da UE: a posição do Parlamento sobre a reforma da regulação de Dublin. Disponível em:

<https://www.europarl.europa.eu/news/pt/headlines/world/20180615STO05927/regras-do-asiloda-ue-posicao-do-parlamento-sobre-a-reforma-da-regulacao-dublin >. Acesso em: 13 mar. 2020.

. Regulamento (CE) no 2725/2000 do Conselho, de 11 de Dezembro de 2000, publicado em Jornal Oficial da União Europeia $n^{\circ}$ L 316/1 de 15 de Dezembro de 2000.Disponível em: <https://eur-lex.europa.eu/legalcontent/PT/TXT/? uri=celex\%3A32000R2725>. Acesso em: 30 out. 2018.

. Regulamento (UE) n 604/2013 do Parlamento Europeu e do Conselho, de 26 de junho de 2013, publicado em Jornal Oficial da União Europeia n $^{\circ}$ L 180/31 de 29 de Junho de 2013. Ressalta-se que a sua entrada em vigor ocorreu em 19 de julho de 2013. Disponível em: <http://eur-lex.europa.eu/legal-content/PT/TXT/?uri=CELEX:32013R0604>. Acesso em: 15 mai. 2018.

. Tratado da União Europeia. Disponível em: <http://publications.europa.eu/resource/cellar/9e8d52e1-2c70-11e6-b49701aa75ed71a1.0019.01/DOC_2>. Acesso em: 07 jul. 2018.

Tratado sobre o Funcionamento da União Europeia. Disponível em: <https://eurlex.europa.eu/legal-content/PT/TXT/? uri=celex\%3A12012E\%2FTXT>. Acesso em: 07 jul. 2018.

ZUNINO, C. Migranti, Salvini chiude i porti "L'Europa si fa gli affari suoi". La Repubblica, Roma, 11 jun. 2018. Disponível em:

<http://ricerca.repubblica.it/repubblica/archivio/repubblica/2018/06/11/migranti-salvini-chiudei-porti-leuropa-si-fa-gli-affari-suoi02.html>. Acesso em: 24 jun. 2018. 


\section{JURISPRUDÊNCIA}

TRIBUNAL DE JUSTIÇA DA UNIÃO EUROPEIA. Acórdão de 06 de setembro de 2017, República Eslovaca e Hungria vs. Conselho da União Europeia (processos apensos C-643/15 e C647/15), ECLI:EU:C:2017:631. Disponível em:

$<$ http://curia.europa.eu/juris/document/document.jsf?text $=\&$ docid $=194081 \&$ pageIndex $=0 \&$ docl ang $=p t \&$ mode $=l s t \& d i r=\& o c c=f i r s t \& p a r t=1 \& c i d=644863>$. Acesso em: 08 jul. 2018. 